\title{
Descubrimiento de la proteína reguladora de apoptosis 2 como determinante en la muerte de células tumorales
}

\author{
Juana Virginia Tapia-Vieyra y Jaime Mas-Oliva* \\ Universidad Nacional Autónoma de México, Instituto de Fisiología Celular, Ciudad de México, México
}

\section{Resumen}

El cáncer es una enfermedad multifactorial que constituye un problema de salud pública mundial. Las etapas avanzadas del cáncer de próstata están asociadas con el desarrollo de tumores independientes de andrógeno y un fenotipo resistente a la apoptosis que progresa a metástasis. Al estudiar células de cáncer de próstata de nódulo linfoide (LNCaP) independientes de andrógeno inducidas a la apoptosis por eliminación de suero, identificamos la activación de un canal catiónico no selectivo de 23pS de conductancia que promueve corrientes entrantes de $\mathrm{Ca}^{2+}$ así como las etapas finales de la apoptosis. El cDNAarp2 fue aislado e identificado del mismo tipo celular y el ARN mensajero fue expresado en ovocitos de Xenopus laevis, asociándolo con la activación de las corrientes entrantes de $\mathrm{Ca}^{2+}$ y la inducción a la apoptosis. El ADN complementario que codifica para la proteína reguladora de apoptosis 2 (ARP2) fue sobreexpresado en células LNCaP y células de ovario de hámster chino, induciendo apoptosis. Nuestra evidencia sugiere que la sobreexpresión y tránsito de la proteína ARP2 a la membrana celular permite una corriente de entrada de $\mathrm{Ca}^{2+}$ aumentada, iniciadora del proceso de apoptosis en células de tipo epitelial cuyo fenotipo muestra resistencia a la muerte celular programada.

PALABRAS CLAVE: Apoptosis. Proteína ARP2. Carcinoma epitelial. Cáncer de próstata.

\begin{abstract}
Cancer is a multifactorial disease that constitutes a serious public health problem worldwide. Prostate cancer advanced stages are associated with the development of androgen-independent tumors and an apoptosis-resistant phenotype that progresses to metastasis. By studying androgen-independent lymphoid nodule carcinoma of the prostate (LNCaP) cells induced to apoptosis by serum elimination, we identified the activation of a non-selective cationic channel of 23pS conductance that promotes incoming $\mathrm{Ca}^{2+}$ currents, as well as apoptosis final stages. arp2cDNA was isolated and identified to be of the same cell type, and mRNA was expressed in Xenopus laevis oocytes, which was found to be associated with the activation of incoming $\mathrm{Ca}^{2+}$ currents and induction to apoptosis. CDNA, which encodes the ARP2 protein, was overexpressed in LNCaP cells and Chinese hamster ovary cells, which induced apoptosis. Our evidence suggests that protein ARP2 overexpression and transit to the cell membrane allows an increased $\mathrm{Ca}^{2+}$ incoming current that initiates the apoptosis process in epithelial-type cells whose phenotype shows resistance to programmed cell death.
\end{abstract}

KEY WORDS: Apoptosis. ARP2 protein. Epithelial carcinoma. Prostate cancer.

E-mail: jmas@ifc.unam.mx
Fecha de recepción: 25-03-2019

Fecha de aceptación: 27-03-2019

DOI: 10.24875/GMM.19005186
Gac Med Mex. 2019;155:546-553

Disponible en PubMed www.gacetamedicademexico.com 


\section{Introducción}

El cáncer es una enfermedad multifactorial y la segunda causa de muerte de la población general en el mundo. Su causalidad está relacionada con los hábitos de vida, predisposición genética y estados psicológico y anímico de los individuos. ${ }^{1}$ La prevalencia del cáncer ha aumentado en los últimos años, por lo que es un problema de salud que demanda un nivel muy alto de atención..$^{2,3}$ En el hombre, los porcentajes más altos de incidencia de cáncer ocurren en próstata, pulmón, bronquios, colon, recto y vejiga urinaria; en las mujeres, en mama, pulmón, bronquios, colon, recto, útero y tiroides. Lo anterior es un indicador de que los tipos de cáncer más comunes en hombres y mujeres, respectivamente, son de próstata y mama. ${ }^{4}$ En los niños, la incidencia más alta en cáncer se observa en médula ósea, cerebro y nódulos linfoides. ${ }^{5,6}$

El cáncer epitelial es uno de los tipos más agresivos. Particularmente en el cáncer de próstata, el tratamiento dependerá de la etapa en que se identifique la enfermedad, sin embargo, es muy común que esta progrese y desarrolle un fenotipo de resistencia a la apoptosis y, por lo tanto, de independencia de la hormona, por lo que las células continúan la proliferación hasta alcanzar la metástasis, de ahí que resulte indispensable el desarrollo de nuevas estrategias terapéuticas que impidan que la enfermedad alcance etapas avanzadas.

Durante el proceso de apoptosis de numerosos tipos de células, el incremento sostenido de $\mathrm{Ca}^{2+}$ citoplásmico ha sido definido como determinante en el inicio de la muerte celular programada. ${ }^{7}$ Considerando este fundamento, desde hace años hemos trabajado en el estudio de los mecanismos de control de la homeostasis del calcio citoplásmico y el impacto del nivel alterado de $\mathrm{Ca}^{2+}$ en diversos tipos celulares y neoplásicos.

Hemos podido demostrar que un nivel aumentado de calcio citoplásmico da como resultado el inicio de la muerte celular programada en líneas celulares epiteliales de cáncer de próstata y de ovario de hámster chino. En este sentido, nuestro grupo de investigación descubrió un canal catiónico no selectivo permeable a $\mathrm{Ca}^{2+}$ de 23pS de conductancia, expresado en condiciones de apoptosis inducida mediante eliminación del suero del medio de cultivo en células de cáncer de próstata de nódulo linfoide (LNCaP, lymph node carcinoma of the prostate) independientes de andrógeno. ${ }^{8}$ Asimismo, se logró aislar el ADN complementario (ADNc) de células LNCaP que codifica para la proteína reguladora de apoptosis 2 (la cual denominamos ARP2), la cual al ser sobreexpresada induce a la apoptosis en ovocitos de Xenopus laevis y células $L N C a P$ independientes de andrógeno, de donde originalmente fue aislada ARP2. ${ }^{9}$ Se demostró que la sobreexpresión de ARP2 induce la apoptosis de células de ovario de hámster chino. Estos hallazgos demuestran que los niveles aumentados de $\mathrm{Ca}^{2+}$ son una condición indispensable para dar inicio a la apoptosis en diversas líneas celulares de tipo epitelial, por lo que esa proteína pudiera constituir en un futuro una excelente herramienta en el tratamiento de la enfermedad, al evitar la progresión hacia las etapas avanzadas que culminan con un proceso metastásico.

\section{Cáncer de próstata}

El cáncer de próstata es la segunda causa de muerte por cáncer en Estados Unidos y la quinta en el mundo. ${ }^{10-12}$ La prevalencia de esta enfermedad se incrementa conforme la edad avanza. El cáncer de próstata es encontrado durante la autopsia en más de la mitad de hombres de Estados Unidos mayores de 50 años, aunque esta enfermedad haya sido la causa de muerte solo en $3 \%$. Es una enfermedad asintomática hasta la aparición de lesiones metastásicas que generalmente son descubiertas en tejido óseo. Las terapias iniciales para dar tratamiento incluyen cirugía, radiación, uso de inhibidores de la 5-alfa reductasa que promueve la formación de andrógenos más potentes a partir de testosterona. ${ }^{13}$ Los métodos iniciales de tratamiento a menudo causan disfunción sexual, urinaria e intestinal. ${ }^{14}$

Desde el punto de vista molecular, esta enfermedad se manifiesta en etapas tempranas y tardías. En las primeras, la proliferación de las células prostáticas es lenta y dependiente de los andrógenos, por lo que durante el tratamiento con agentes quimioterapéuticos las células alcanzan a reparar el daño y continúan proliferándose. Con el tiempo, las células se independizan de las hormonas androgénicas para proliferar, por lo que culminan en el desarrollo de metástasis que lleva al paciente a la muerte..$^{15}$

\section{Apoptosis y enfermedad}

La muerte celular programada 0 apoptosis es un evento celular intrínseco de relevante importancia en procesos como la homeostasis celular, el desarrollo 
embrionario y el inicio y mantenimiento de varias enfermedades como el cáncer y la aterosclerosis. ${ }^{16,17}$ Este mecanismo se desarrolla mediante dos vías; la del receptor de muerte celular y la vía mitocondrial. ${ }^{18}$ A su vez, el proceso apoptótico se desarrolla en varias etapas: la primera se relaciona con los estímulos que disparan la muerte celular programada, la segunda involucra los procesos de transducción de las señales, en la tercera participan enzimas efectoras que se ocupan del desensamble celular, como las caspasas activas y, finalmente, en la cuarta ocurre la condensación de la cromatina, la degradación del ADN y la formación de los cuerpos apoptóticos. ${ }^{18,19}$

Existen diversas vías apoptóticas como la extrínseca 0 de receptor de muerte, cuya caspasa iniciadora es la caspasa 8, y la intrínseca o mitocondrial, que tiene como proteína intermediaria al citocromo $\mathrm{C}$ y a la caspasa 9 como iniciadora. Ambas pueden converger en el conjunto de caspasas efectoras, principalmente las caspasas 3 y 7 , que se activan a través del autoprocesamiento o activación en cascada, por lo que las mismas caspasas se autoactivan y activan entre ellas. ${ }^{20,21}$ Existe otra vía alternativa denominada de la perforina-granzima, ${ }^{22,23}$ que corresponde a un complejo de serina proteasas importante en la apoptosis inducida mediante células T citotóxicas, activando vías independientes de caspasas.

\section{$\mathrm{Ca}^{2+}$ como segundo mensajero determinante en el proceso de apoptosis}

Las variaciones en la concentración del $\mathrm{Ca}^{2+}$ intracelular promueven el comienzo de eventos celulares como la regulación del metabolismo, la mitosis, la secreción de neurotransmisores y de hormonas, así como la contracción de miofilamentos, por lo que se considera un segundo mensajero determinante para las funciones celulares. ${ }^{24,25}$ Los niveles de $\mathrm{Ca}^{2+}$ también están involucrados en los mecanismos regulatorios de la muerte celular programada apoptótica. ${ }^{26,27}$ Un nivel de $\mathrm{Ca}^{2+}$ superior al basal se considera altamente tóxico, ya que genera la activación de proteasas y fosfolipasas que participan en el desensamble celular. ${ }^{28} \mathrm{El}$ incremento de $\mathrm{Ca}^{2+}$ puede ocurrir en etapas tempranas y tardías de la apoptosis, mediante la salida de $\mathrm{Ca}^{2+}$ del retículo endoplásmico y la entrada de $\mathrm{Ca}^{2+}$ al citoplasma a través de canales activados por liberación de $\mathrm{Ca}^{2+}$. ${ }^{29}$ Es necesario tener en cuenta que parte del $\mathrm{Ca}^{2+}$ intracelular se mueve al retículo endoplásmico a través de la bomba de calcio del retículo endoplásmico y el $\mathrm{Ca}^{2+}$ es liberado de estos almacenes por receptores inositol 1,4,5 trifosfato o receptores de rianodina. Adicionalmente, en diversos organelos intracelulares (como el aparato de Golgi, núcleo y mitocondria) existen sistemas especializados para el transporte de $\mathrm{Ca}^{2+} .30$

El calcio entra a la célula a través de proteínas transmembranales llamadas canales de calcio. ${ }^{31}$ El calcio pasa a través de los canales mediante mecanismos distintos dependiendo del tipo de canal o voltaje o bien a través de receptores; estas vías no requieren energía, a diferencia de las bombas de calcio que envían calcio citoplásmico al exterior de la célula a expensas de la utilización de adenosín trifosfato.

En colaboración con el doctor Agustín Guerrero del CINVESTAV, en el laboratorio del Instituto de Fisiología Celular, Universidad Nacional Autónoma de México, para la obtención de registros electrofisiológicos se combinó técnica de fijación de membranas (patch clamp) y mediciones simultáneas de $\mathrm{Ca}^{2+}$ en célula única, con el propósito de estudiar la activación de canales permeables a $\mathrm{Ca}^{2+}$ mediante el uso de dos diferentes inductores: un ionóforo (ionomicina) y la eliminación del suero. ${ }^{8}$ La última priva a las células de componentes nutricionales esenciales como proteínas, factores de crecimiento y vitaminas, induciendo a las células a la muerte. ${ }^{32,33}$

Los resultados demostraron la activación de un canal catiónico no selectivo y permeable a $\mathrm{Ca}^{2+}$ de $23 p S$ de conductancia. Los niveles aumentados de $\mathrm{Ca}^{2+}$ indujeron a las células a la apoptosis, lo cual demostró que la activación de este canal promueve el desarrollo de la muerte programada de las células LN-CaP, lo que constituyen un importante hallazgo para la inducción de la muerte programada en este tipo celular (Figura 1).

Continuando con esta línea de investigación, en nuestro grupo se aisló, identificó y caracterizó cDNAarp2, que codifica para ARP2 de células LNCaP independientes de andrógeno, inducidas a la apoptosis mediante la eliminación del suero. ${ }^{9}$ La secuencia de esta proteína muestra homología con el factor de empalme o splicing Prp8 (un componente del spliceosoma $)^{34}$ y funciones proapoptóticas en distintos tipos celulares (Figura 2). El mecanismo de corte y empalme de tipo alternativo es definido como una propiedad que prevalece en los organismos superiores para producir proteínas múltiples de un gen simple. ${ }^{35,36} \mathrm{La}$ actividad de unión a ubiquitina de la proteína Prp8 sugiere que algunos factores de corte y empalme para el pre-mARN pueden ser ubiquitinados para tener una interacción con Prp8. ${ }^{37}$ 
A

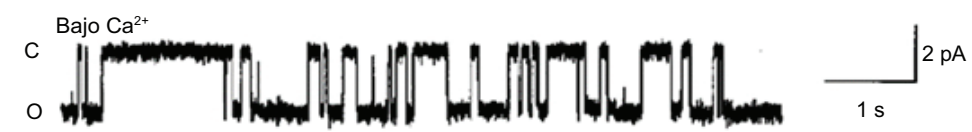

B

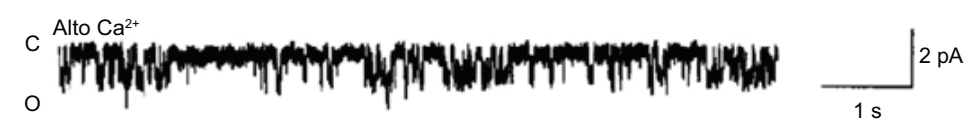

C

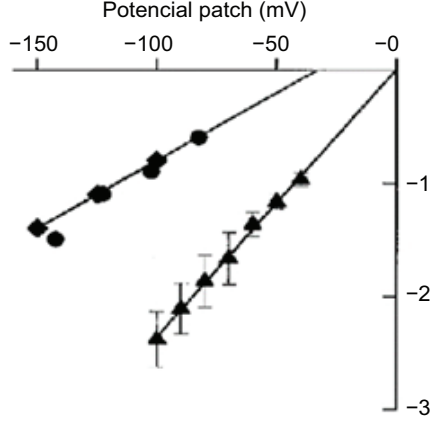

D

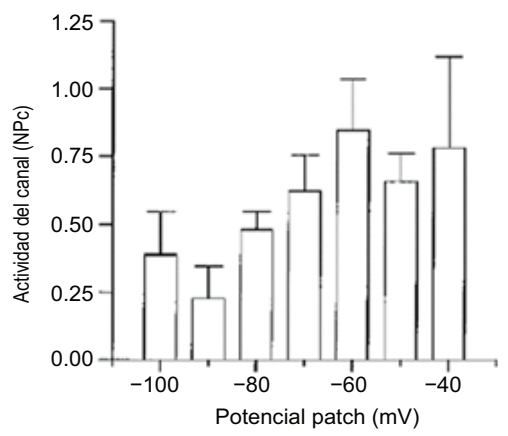

Figura 1. Caracterización de canales iónicos asociados con el segundo aumento en $\mathrm{Ca}^{2+}$. A: Registros de corriente de canal simple en la configuración de célula adherida con un potencial patch de $-100 \mathrm{mV}$ y solución de $\mathrm{Na}^{+}-\mathrm{Ca}^{2+}$; B: Registros de canal simple con $110 \mathrm{mM} \mathrm{de} \mathrm{CaCl}{ }_{2}$ en la solución de la pipeta y un potencial patch de $-100 \mathrm{mV}$. En el lado izquierdo del registro se indican los niveles cerrado (C) y abierto (O); C: Curvas de corriente-voltaje obtenidas en solución $\mathrm{Na}^{+} \mathrm{Ca}^{2+}(\mathbf{\Delta}), 110 \mathrm{mM} \mathrm{de} \mathrm{CaCl}_{2}(\bullet)$ o $110 \mathrm{mM}$ de calcio glutamato (•) como transportadores de carga; D: En los potenciales de membrana indicados $(n=4)$ se muestra media \pm desviación estándar de la actividad de estado basal del canal de 23pS. Tomada de referencia 8.

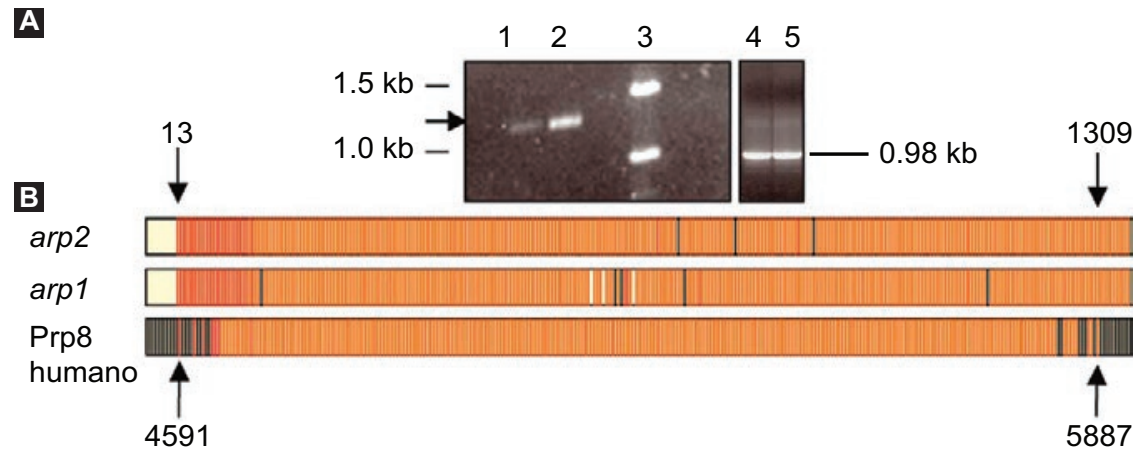

Figura 2. Clonación de arp1 y arp2. A: Agarosa a $1 \%(\mathrm{w} / \mathrm{v})$, productos de la reacción en cadena de la polimerasa de las clonas arp2. Carril 1, producto de las células creciendo en la presencia de suero (control). Carril 2, producto de las células cultivadas en la ausencia de suero. Carril 3 , marcadores de peso molecular (GIBCO BRL, ADN $1 \mathrm{~kb}$ ). Carriles 4 y 5, controles GAPDH; B: Alineamiento múltiple de ADNc arp1 y arp2 con el ADNc Prp8 humano. Los nucleótidos 4591-5887 corresponden a la región de Prp8 humano que sobrelapa con secuencias de los ADNc arp1 y arp2. Las líneas negras indican los nucleótidos que no muestran homología entre los ADNc. Los espacios amarillos entre las líneas rojas corresponden a espacios vacíos de nucleótidos entre los ADNc. Las flechas negras señalan los nucleótidos 13 y 1309 de arp1 y arp2 y los nucleótidos 4591 y 5887 de Prp8. Tomada de referencia 9.

Ovocitos de la rana Xenopus laevis inyectados con el mARN de arp2 presentaron formación de ampollas a partir de las 12 horas de la inyección; se observó que estos cambios morfológicos aumentan cuando los ovocitos son tratados con tapsigargina (Figura 3A y 3B, respectivamente). También fue posible observar que los ovocitos sufrieron disminución en el potencial de membrana en reposo: de un valor control de $-46.8 \pm 6.6 \mathrm{mV}$ pasaron a $-5.9 \pm 3.4 \mathrm{mV}$ (5-8 ovocitos, dos ranas) (Figura 4). La incubación de las células con tapsigargina aceleró y aumentó los cambios morfológicos, siendo evidente la pérdida de la definición de los polos animal y vegetal, que se observó a las 36 horas de la inyección con el mARN arp2 y ocho horas después de la incubación con tapsigargina (Figura 3B).

Los cambios morfológicos y la depolarización membranal observados en nuestro estudio han sido descritos en ovocitos de Xenopus laevis cuando son inyectados con citocromo C para disparar el 

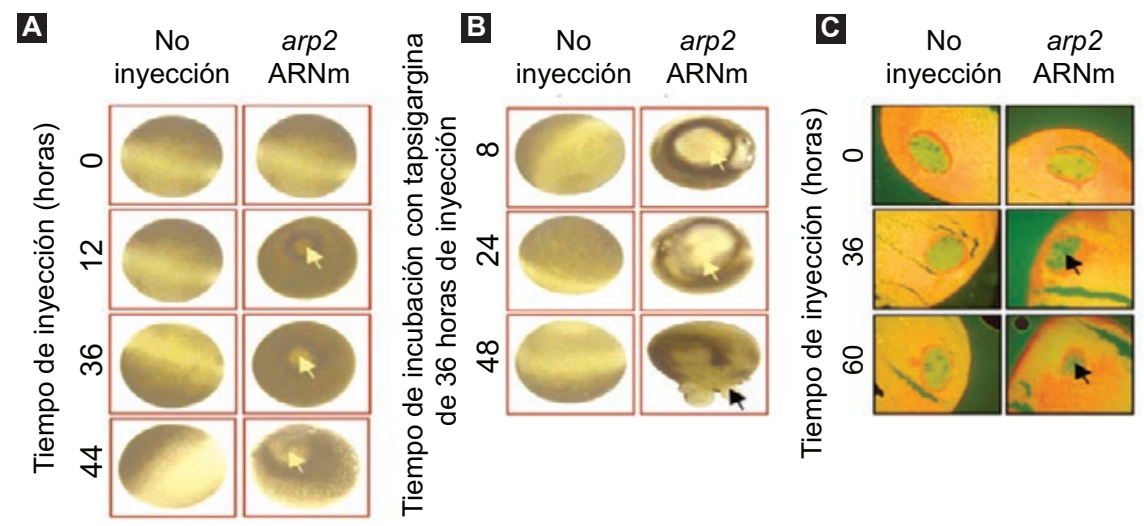

Figura 3. Cambios morfológicos de ovocitos de Xenopus laevis relacionados con apoptosis después de la inyección del ARNm arp2; A: Inducción de apoptosis en ovocitos de Xenopus laevis por microinyección de ARNm arp2. Las columnas verticales corresponden a ovocitos que no recibieron inyección y ovocitos inyectados con ARNm arp2. Las líneas horizontales muestran los tiempos de inyección (0, 12, 36, 44 horas). Las flechas amarillas muestran las ampollas formadas; B: Progresión de la muerte celular en ovocitos de Xenopus laevis inyectados con el ARNm arp2 y la incubación con $5 \mu \mathrm{M}$ de tapsigargina. Las columnas verticales muestran ovocitos control que no recibieron inyección y ovocitos inyectados con ARNm. Las líneas horizontales muestran los tiempos de incubación con tapsigargina de 36 horas de inyección y 8, 24, y 48 horas de incubación con tapsigargina; C: Cambios morfológicos en el núcleo de ovocitos de Xenopus laevis observados después de la inyección de ARNm arp2. Las columnas verticales muestran secciones histológicas de ovocitos no inyectados y ovocitos inyectados con ARNm arp2. Las líneas horizontales muestran tiempo de incubación después de la inyección de $\operatorname{ARNm}(0,36,60$ horas) Las flechas negras muestran la condensación de la cromatina. Tomada de referencia 9.

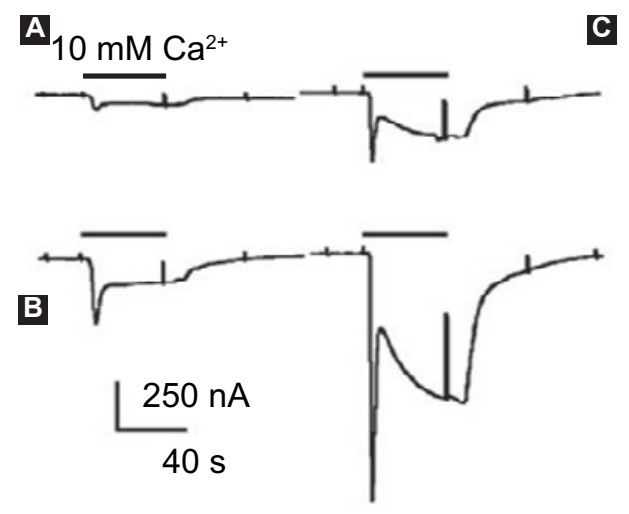

C

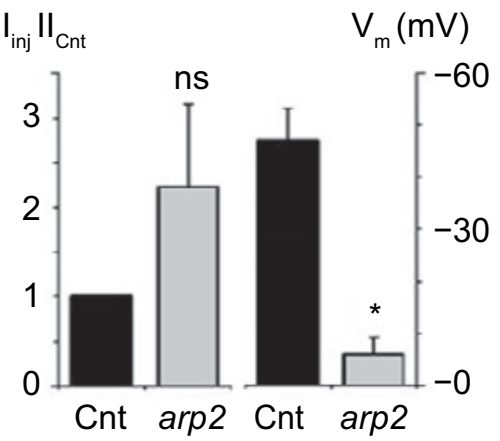

Figura 4. Expresión funcional del ARNm arp2 en ovocitos de Xenopus laevis. Corrientes iónicas generadas por dos pulsos consecutivos de $10 \mathrm{mM} \mathrm{Ca}^{2+}$ en solución Ringer-Mg ${ }^{2+}$ después de la incubación de los ovocitos en ausencia de $\mathrm{Ca}^{2+}$ y en presencia de $5 \mu \mathrm{M}$ de tapsigargina; A: Corrientes entrantes generadas en un ovocito control no inyectado; B: Corriente en un ovocito inyectado con ARNm arp2. Histograma que muestra la media \pm desviación estándar de la corriente generada en ovocitos control $(n=3)$ y ovocitos inyectados con el $A R N m$ arp2 $(n=6)$. También se muestran los cambios en el potencial de reposo $(\mathrm{Vm})$ observados entre los diferentes grupos de ovocitos (ocho control y seis inyectados). Todos los ovocitos de esta figura fueron del mismo donador; resultados similares fueron obtenidos de una segunda rana. Cnt = control, ns $=$ no significativo, ${ }^{*} p \leq 0.05$. Tomada de referencia 9 .

mecanismo apoptótico, ${ }^{38}$ al igual que en ovocitos inyectados con la molécula proapoptótica $\mathrm{Bcl}-\mathrm{xs}^{9,39}$ La tapsigargina, un fármaco que descarga los almacenes intracelulares de $\mathrm{Ca}^{2+}$ por la inhibición específica de la $\mathrm{Ca}^{2+}$-ATPasa del retículo endoplásmico, provoca que se activen canales independientes de voltaje de la membrana citoplasmática (TRP, transient receptor potential). ${ }^{40}$

De esta forma hemos reunido evidencia suficiente de que ARP2 es promotora de la apoptosis en las células LNCaP independientes de andrógeno y en células epiteliales de ovario de hámster chino, ${ }^{41}$ favoreciendo incrementos mantenidos de $\mathrm{Ca}^{2+}$ al interactuar directamente con canales de membrana permeables a $\mathrm{Ca}^{2+}$ o presentando una función de canal de membrana. Por otro lado, considerando la homología de la secuencia del ADNc que codifica para ARP2 con el factor de corte y empalme Prp8, hasta el momento se desconoce si esta proteína pudiera tener adicionalmente alguna participación en el ensamble o funcionamiento del spliceosoma o estar relacionada con los mecanismos de regulación de corte y empalme alternativo de los ARNm que codifican para las proteínas de la maquinaria apoptótica. Existe 

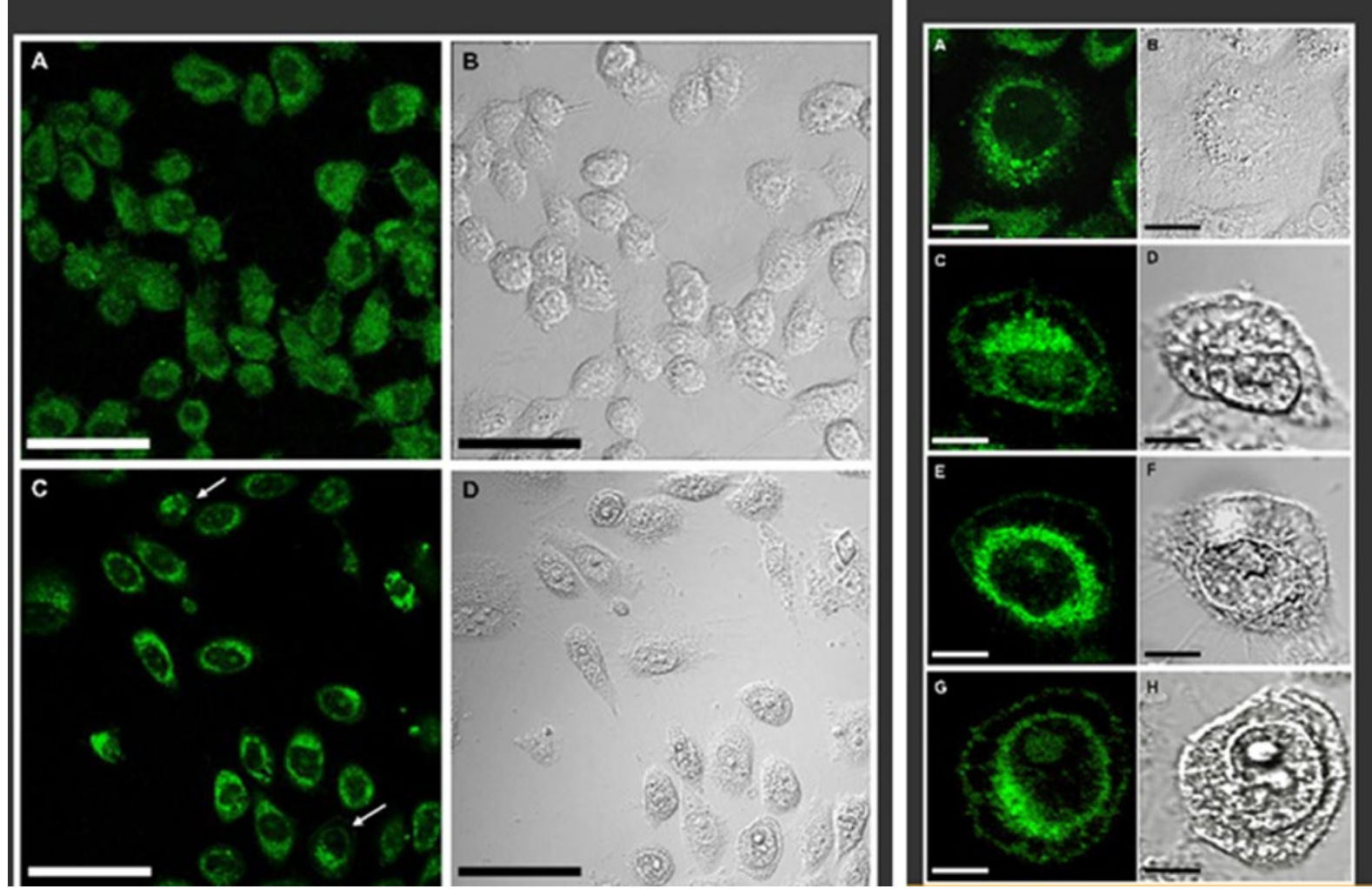

Figura 5. Microscopia confocal de la proteína de fusión ARP2 expresada en células de ovario de hámster chino (CHO). Células $\mathrm{CHO}$ transfectadas con egfp ADNc fueron observadas 24 horas postransfección. A: Microscopia diferencial de contraste de interferencia; B: Células CHO transfectadas con arp2-egfp ADNc también fueron observadas 24 horas postransfección; C: Microscopia diferencial de contraste de interferencia; D: Escala de la barra $50 \mu \mathrm{m}$. Flechas blancas indican que ARP2 se localiza en la región perinuclear. Lado derecho: las células $\mathrm{CHO}$ transfectadas con ADNc arp2-egfp examinadas a las 16, 24, 48 y 72 horas postransfección (A, C, E y G, respectivamente); lo anterior pero con microscopia diferencial de contraste de interferencia (B, D, F y H, respectivamente). Escala de la barra $10 \mu \mathrm{m}$. Tomada de referencia 41.

un estudio en el que se observó que la proteína Prp8 se une a uno de los dominios del receptor a andrógeno de células de cáncer de próstata y, en consecuencia, pudiera estar interviniendo en la funcionalidad de este durante el desarrollo de la enfermedad..$^{42}$ Asimismo, se reportó que algunos factores de corte y empalme que conforman el spliceosoma están vinculados con el desarrollo de cáncer de mama, como el factor SNW1. ${ }^{43}$

Continuando con el proyecto, el ADNc que codifica para ARP2 fue clonado en un plásmido de expresión y transfectado a células LNCaP independientes de andrógeno y células de ovario de hámster chino. La sobreexpresión de ARP2 indujo a las células a desarrollar apoptosis, con impacto importante sobre la viabilidad celular y la activación de las caspasas efectoras 3 y 7 , resultados comparados con los de células en inanición y tratadas con ionomicina. ${ }^{41}$ En este estudio fue posible evidenciar mediante microscopia confocal que ARP2 inicialmente está localizado en la región perinuclear de las células y migra a lo largo del tiempo a la membrana plasmática ${ }^{41}$ (Figuras 6).
Tomando en cuenta nuestros resultados, consideramos que ARP2 se inserta en la membrana plasmática, con una función semejante a la de un canal de membrana, de esta forma constituye un blanco valioso para modular el flujo y la concentración de $\mathrm{Ca}^{2+}$ en el citoplasma de células de cáncer epitelial que muestran un fenotipo resistente a la apoptosis ${ }^{41}$ (Figura 6).

\section{Perspectivas}

El mecanismo de apoptosis en fenotipos celulares malignos resistentes ha sido tema de amplio estudio en los últimos años. Debido al fuerte impacto del desarrollo del cáncer, es urgente la implementación de estrategias moleculares exitosas que apoyen los tratamientos contra esta enfermedad. Nuestro grupo ha demostrado que la sobreexpresión de la proteína ARP2 induce la muerte celular programada de diferentes tipos celulares: células de cáncer de próstata de nódulo linfoide independientes de andrógeno, de donde originalmente fue aislada, células de ovario de hámster chino, células de riñón embrionario humano 


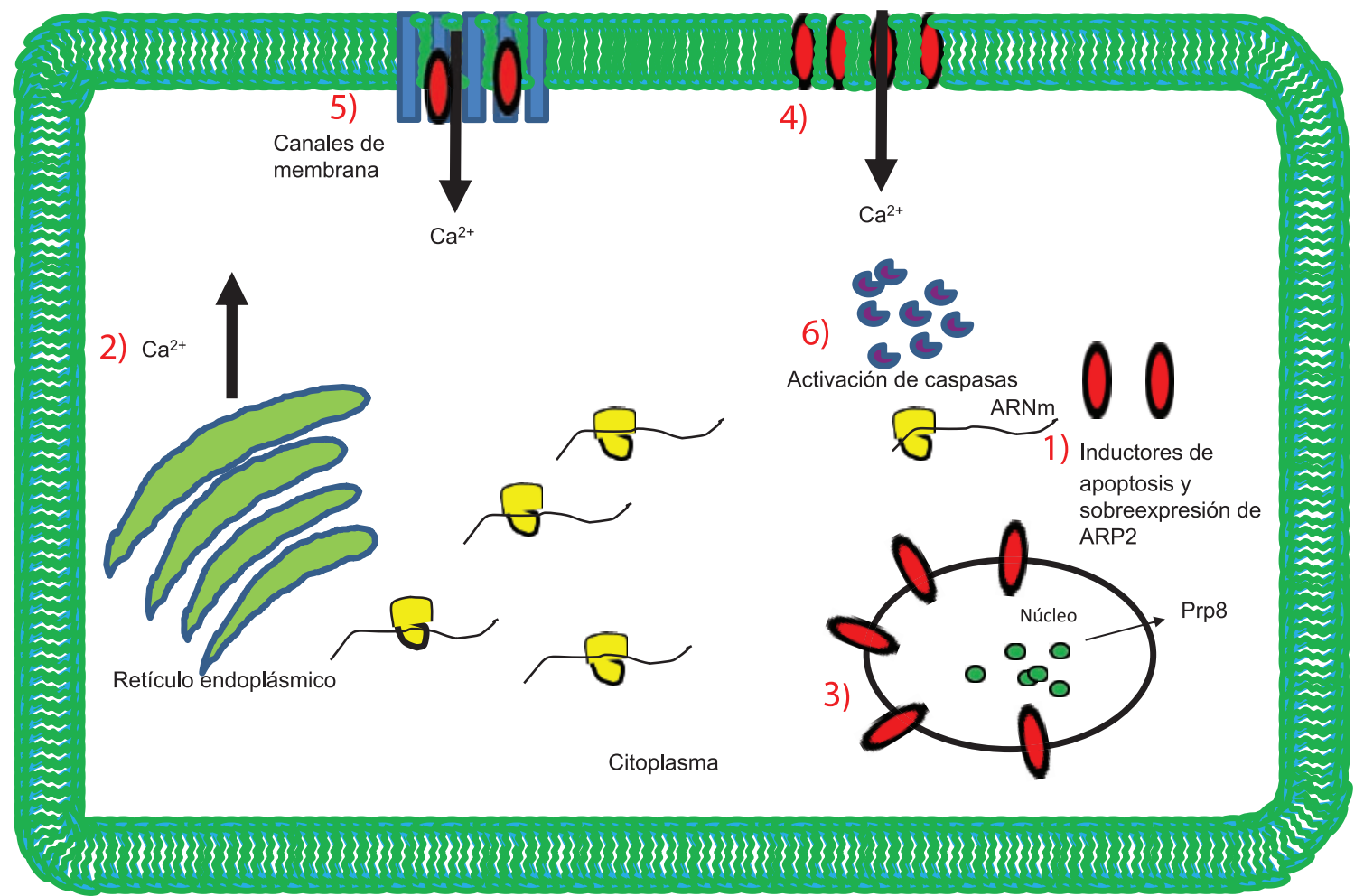

Figura 6. Modelo de acción de ARP2. 1: Inductores de apoptosis y sobreexpresión de ARP2; 2: La sobreexpresion de ARP2 promueve incremento de $\mathrm{Ca}^{2+}$ proveniente de retículo endoplásmico y membrana citoplasmática; 3: ARP2 localizada en membrana perinuclear en interacción con el complejo del spliceosoma, lo que promueve influjos de $\mathrm{Ca}^{2+}$; 4 : ARP2 insertándose en la membrana citoplasmática, con lo que forma posibles canales de membrana o regula la activación de canales permeables a $\mathrm{Ca}^{2+}(\mathbf{5})$; estos influjos de $\mathrm{Ca}^{2+}$ favorecen la actividad del complejo del spliceosoma y el desarrollo del mecanismo de apoptosis (6).

y células endoteliales de arteria coronaria (datos no mostrados).

Dadas las evidencias experimentales reunidas, consideramos que ARP2 pudiera estar contribuyendo durante su sobreexpresión al incremento de los niveles intracelulares de $\mathrm{Ca}^{2+}$ como una molécula mensajera o como una proteína insertada en la membrana que favorece la entrada de $\mathrm{Ca}^{2+}$. Además de encontrarse en la región membranal, también observamos su localización perinuclear y debido a la homología con el factor Prp8 cabe la posibilidad de que esté participando en los mecanismos de corte y empalme alternativo de moléculas proapoptóticas. ${ }^{44-46}$ En este sentido y tomando en cuenta de que la transcripción a través de mecanismos de corte y empalme alternativos son procesos moleculares altamente regulados por el nivel intracelular de $\mathrm{Ca}^{2+}$, entre otros, ${ }^{47,48}$ es factible pensar que ARP2 pudiera tener una doble función: en el control del flujo plasmático de $\mathrm{Ca}^{2+} \mathrm{y}$ en mecanismos moleculares de corte y empalme alternativo.

Con fundamento en la evidencia de que genes de muerte celular están desregulados en el cáncer, fenómeno asociado con el control de sus patrones de corte y empalme alternativo, es justificado pensar que el proceso de apoptosis se manifiesta como una respuesta positiva a la quimioterapia. ${ }^{49} \mathrm{Si}$ tomamos en cuenta que la eficacia de los fármacos contra el cáncer puede también depender de la activación de la apoptosis o de una forma de inducción aguda de senescencia celular, consideramos que la sobreexpresión de la proteína ARP2 potencialmente podría ser empleada como una nueva herramienta en el tratamiento del cáncer de tipo epitelial.

\section{Bibliografía}

1. Vineis $P$, Wild $C P$. Global cancer patterns: causes and prevention. Lancet. 2014;383:549-557.

2. Siegel R, Naishadham D, Jemal A. Cancer statistics, 2013. CA Cancer J Clin. 2013;63:11-30.

3. Hossein-Hassanpour S, Dehghani M. Review of cancer from perspective of molecular. J Cancer Res Pract. 2017;4:127-129.

4. Siegel RL, Miller KD, Jemal A. Cancer statistics, 2016. CA Cancer J Clin. 2016;66:7-30.

5. Schottenfeld D, Fraumeni JF. Cancer epidemiology and prevention. Inglaterra: Oxford Scholarship Online; 2006.

6. Yoo KY, Shin HR. Cancer epidemiology and prevention. Korean J Epidemiol. 2003;25:1-15.

7. Pinton P, Giorgi C, Siviero R, Zecchini E, Rizzuto R. Calcium and apoptosis: ER-mitochondria $\mathrm{Ca} 2+$ transfer in the control of apoptosis. Oncogene. 2008;27:6407-6418.

8. Gutiérrez AA, Arias JM, García L, Mas-Oliva J, Guerrero-Hernández A. Activation of a $\mathrm{Ca} 2+$ permeable cation channel by two different inducers of apoptosis in a human prostatic cancer cell line. J Physiol. 1999;15:95-107. 
9. Tapia-Vieyra JV, Arellano RO, Mas-Oliva J. ARP2 a novel protein involved in apoptosis of LNCaPcells shares a high degree homology with splicing factor Prp8. Mol Cel Biochem. 2005;269:189-201.

10. Ferlay J, Soerjomataram I, Dikshit R, Eser S, Mathers C, Rebelo M et al. Cancer incidence and mortality worldwide: sources, methods and major patterns in GLOBOCAN 2012. Int J Cancer. 2015;136:E359-E386.

11. Dall'Era MA, Albertsen PC, Bangma C, Carroll PR, Carter HB, Cooperberg MR, et al. 2012. Active surveillance for prostate cancer: a systematic review of the literature. Eur Urol. 2012;62:976-983.

12. Siegel RL, Miller KD, Jemal A. Cancer statistics, 2015. CA Cancer J Clin. 2015;65:5-29

13. Thompson IM, Goodman PJ, Tangen CM, Lucia MS, Miller GJ, Ford LG, et al. The influence of finasteride on the development of prostate cancer. N Engl J Med. 2003;349:215-224.

14. Talcott JA. In the clinic. Prostate cancer. Ann Intern Med. 2015;163:ITC1 ITC12.

15. Quinn DI, Sandler HM, Horvath LG, Goldkorn A, Eastham JA. The evolution of chemotherapy for the treatment of prostate cancer. Ann Oncol. 2017;28:2658-2669.

16. Kerr JF, Wyllie AH, Currie AR. Apoptosis: a basic biological phenomenon with wide-ranging implications in tissue kinetics. $\mathrm{Br} \mathrm{J}$ Cancer. 1972;26:239-257.

17. Tapia-Vieyra JV, Delgado-Coello B, Mas-Oliva J. Atherosclerosis and cancer; a resemblance with far-reaching implications. Arch Med Res. 2017;48:12-26.

18. Chen M, Wang J. Initiator caspases in apoptosis signaling pathways. Apoptosis. 2002;7:313-319.

19. Cooper KF. Till death do us part: the marriage of autophagy and apoptosis. Oxidative Med Cell Longevity. 2018:1:1-13.

20. Fulda S, Debatin KM. Extrinsic versus intrinsic apoptosis pathways in anticancer chemotherapy. Oncogene. 2006;25:4798-4811.

21. Hassan M, Watari H, AbuAlmaaty A, Ohba Y, Sakuragi N. Apoptosis and molecular targeting therapy in cancer. Biomed Res Int. 2014:2014:150845.

22. Elmore S. Apoptosis: a review of programmed cell death. Toxicol Pathol. 2007;35:495-516

23. Adams JM. Ways of dying: multiple pathways to apoptosis. Genes Dev. 2003:17:2481-2495

24. Mason RP. Calcium channel blockers, apoptosis and cancer: is there a biologic relationship? J Am Coll Cardiol. 1999:34:1857-1866.

25. Clapham DE. Calcium signaling. Cell. 2007:131:1047-1058.

26. Rizzuto R, Pinton P, Ferrari D, Chami M, Szabadkai G, Magalhães PJ, et al. Calcium and apoptosis: facts and hypotheses. Oncogene. 2003;22:8619-8627.

27. Giorgi C, Romagnoli A, Pinton P, Rizzuto R. Ca2+ signaling, mitochondria and cell death. Curr Mol Med. 2008;8:119-130.

28. Fariss MW, Pascoe GA, Reed DJ. Vitamin E reversal of the effect of extracellular calcium on chemically induced toxicity in hepatocytes. Science. 1985:227:751-754

29. Pinton P, Rizzuto R. Bcl-2 and $\mathrm{Ca} 2+$ homeostasis in the endoplasmic reticulum. Cell Death Differ. 2006;13:1409-1418.

30. Görlach A, Bertram K, Hudecova S, Krizanova O. Calcium and ROS: a mutual interplay. Redox Biol. 2015;6:260-271.
31. Tapia-Vieyra JV, Mas-Oliva J. Apoptosis and cell death channels in prostate cancer. Arch Med Res. 2001;32:175-185

32. Schamberger CJ, Gerner C, Cerni C. Caspase-9 plays a marginal role in serum starvation-induced apoptosis. Exp Cell Res. 2005:302:115-128.

33. Braun F, Bertin-Ciftci J, Gallouet AS, Millour J, Juin P. Serum-nutrient starvation induces cell death mediated by Bax and Puma that is counteracted by $\mathrm{p} 21$ and unmasked by $\mathrm{Bcl}-\mathrm{xL}$ inhibition. PlosOne. 2011;6:e23577.

34. Kelemen O, Convertini P, Zhang Z, Wen Y, Shen M, Falaleeva M, et al. Function of alternative splicing. Gene. 2017;514:1-30.

35. Black DL. Mechanisms of alternative pre-messenger RNA splicing. Annu Rev Biochem. 2003;72:291-336.

36. Blencowe BJ. Alternative splicing: new insights from global analyses. Cell. 2006:126:37-47.

37. Bellare P, Kutach AK, Rines AK, Guthrie C, Sontheimer EJ. Ubiquitin binding by a variant Jab1/MPN domain in the essential pre-mRNA splicing factor Prp8p. RNA. 2006;12:292-302.

38. Bhuyan AK, Varshney A, Mathew MK. Resting membrane potential as a marker of apoptosis: studies of xenopus oocytes microinjected with cytochrome c. Cell Death Differ. 2001;8:63-69.

39. Braun T, Dar S, Vorobiov D, Lindenboim L, Dascal N, Stein R. 2003. Expression of $\mathrm{Bcl}-\mathrm{x}(\mathrm{S})$ in xenopus oocytes induces $\mathrm{BH}$-dependent and caspase-dependent cytochrome $\mathrm{c}$ release and apoptosis. Mol Cancer Res. 2003:1:186-194.

40. Boulay G, Zhu X, Peyton M, Jiang M, Hurst R, Enrico S, et al. Cloning and expression of a novel mammalian homolog of Drosophila transient receptor potential (Trp) involved in calcium entry secondary to activation of receptors coupled by the $G_{q}$ class of $G$ protein. $J$ Biol Chem. 1997;272:29672-29680.

41. Mas-Oliva J, Navarro-Vidal E, Tapia-Vieyra JV. ARP2, a novel pro-apoptotic protein expressed in epithelial prostate cancer LNCaP cells and epithelial ovary CHO transformed cells. PLoS One. 2014;9:e86089.

42. Wang D, Nguyen MM, Masoodi KZ, Singh P, Jing Y, O'Malley K, et al Splicing factor Prp8 interacts with NES(AR) and regulates androgen receptor in prostate cancer cells. Mol Endocrinol. 2015;29:1731-1742.

43. Sato N, Maeda M, Sugiyama M, Ito S, Hyodo T, Masuda A, et al. 2015. Inhibition of SNW1 association with spliceosomal proteins promotes apoptosis in breast cancer cells. Cancer Med. 2015;4:268-277.

44. Maniatis T, Tasic B. Alternative pre-mRNA splicing and proteome expansion in metazoans. Nature. 2002:418:236-243.

45. Schwerk C, Schulze-Osthoff K. Regulation of apoptosis by alternative pre-mRNA splicing. Mol Cell. 2005;19:1-13.

46. Moore MJ, Wang Q, Kennedy CJ, Silver PA. An alternative splicing network links cell-cycle control to apoptosis. Cell. 2010;142:625-636.

47. Krebs $\mathrm{J}$. The influence of calcium signaling on the regulation of alternatives splicing. Biochim Biophys Acta. 2009:1793:979-984.

48. Tarn WY. Cellular signals modulate alternative splicing. J Biomed Sci. 2007; $14: 517-522$.

49. Bracco L, Kearsey J. The relevance of alternative RNA splicing to pharmacogenomics. Trends Biotechnol. 2003;21:346-353. 